\title{
All-SiC Fiber-Optic Sensor Based on Direct Wafer Bonding for High Temperature Pressure Sensing
}

\author{
Ting LIANG ${ }^{1}$, Wangwang $\mathrm{LI}^{2,3^{*}}$, Cheng $\mathrm{LEI}^{1}$, Yongwei $\mathrm{LI}^{1}$, \\ Zhiqiang $\mathrm{LI}^{1}$, and Jijun XIONG ${ }^{1}$
}

\author{
${ }^{1}$ Science and Technology on Electronic Test \& Measurement Laboratory, North University of China, Taiyuan 030051, \\ China \\ ${ }^{2}$ Department of Physics, Taiyuan Normal University, Jinzhong 030619, China \\ ${ }^{3}$ Institute of Computational and Applied Physics, Taiyuan Normal University, Jinzhong 030619, China \\ ${ }^{*}$ Corresponding author: Wangwang LI_ E-mail: 18434365707@163.com
}

\begin{abstract}
This paper presents an all-SiC fiber-optic Fabry-Perot (FP) pressure sensor based on the hydrophilic direct bonding technology for the applications in the harsh environment. The operating principle, fabrication, interface characteristics, and pressure response test of the proposed all-SiC pressure sensor are discussed. The FP cavity is formed by hermetically direct bonding of two-layer $\mathrm{SiC}$ wafers, including a thinned $\mathrm{SiC}$ diaphragm and a $\mathrm{SiC}$ wafer with an etched cavity. White light interference is used for the detection and demodulation of the sensor pressure signals. Experimental results demonstrate the sensing capabilities for the pressure range up to $800 \mathrm{kPa}$. The all-SiC structure without any intermediate layer can avoid the sensor failure caused by the thermal expansion coefficient mismatch and therefore has a great potential for pressure measurement in high temperature environments.
\end{abstract}

Keywords: $\mathrm{SiC}$; pressure sensor; optical-fiber; high temperature; direct bonding

Citation: Ting LIANG, Wangwang LI, Cheng LEI, Yongwei LI, Zhiqiang LI, and Jijun XIONG, "All-SiC Fiber-Optic Sensor Based on Direct Wafer Bonding for High Temperature Pressure Sensing," Photonic Sensors, 2022, 12(2): 130-139.

\section{Introduction}

High temperature pressure sensors that can precisely monitor static and dynamic pressures are of great significance for various industrial and aerospace systems under extremely harsh environments, such as turbine engines and high-speed aircraft [1]. For example, in a jet engine, the fuel efficiency and other performance of the jet engine can be improved by accurately monitoring the pressure in the combustion chamber in real time $[2,3]$. Conventional silicon-based and even silicon-on-insulator (SOI)-based pressure sensors cannot operate in environments with temperatures exceeding $500{ }^{\circ} \mathrm{C}$ due to high temperature deformation of the material $[4,5]$. Silicon carbide (SiC) has been considered a better candidate than silicon for high-temperature applications due to its excellent mechanical robustness, chemical inertness, radiation resistance, and electrical stability at elevated temperatures [6-8]. SiC-based high-temperature pressure sensors based on piezoresistive and capacitive detection mechanisms have demonstrated sensing capabilities in the temperature range of $350{ }^{\circ} \mathrm{C}-600{ }^{\circ} \mathrm{C}$ [9-12]. However, these sensors cannot perform well under

Received: 27 January 2021 / Revised: 02 July 2021

(C) The Author(s) 2021. This article is published with open access at Springerlink.com DOI: $10.1007 / \mathrm{s} 13320-021-0640-7$

Article type: Regular 
harsh environments due to many inherent problems such as strong high temperature dependence, electromagnetic interference, and poor performance in long-term stability and repeatability.

Compared with the electrical sensors, fiber-optic pressure sensors are tolerant to extreme temperature and can offer immunity to electromagnetic interference (EMI), high sensitivity, electrical passivity, and good long-term stability [13-18]. Among them, diaphragm-based extrinsic Fabry-Perot interferometer (EFPI) sensors have been widely investigated for their high resolution and precision, ease of manufacture, and excellent survivability in harsh environments [19-24]. Pulliam et al. [25] proposed an all-SiC pressure sensor fabricated by a deposited $\mathrm{SiC}$ diaphragm and a single-crystal $\mathrm{SiC}$ substrate. However, the pressure sensor shows a nonlinear response due to the internal stress left in the membrane. Jiang et al. [26] reported an all-SiC pressure sensor fabricated via an ultrasonic vibration mill-grinding and a nickel diffusion bonding method. However, the leakage rate of the sensor cavity is significantly increased at elevated temperatures due to the imperfect bonding process.

In this paper, we propose an all-SiC EFPI pressure sensor based on the hydrophilic direct bonding technology for high temperature applications. The sensor head is formed by direct hermetically bonding of two-layer $\mathrm{SiC}$ wafers including a $\mathrm{SiC}$ diaphragm and a $\mathrm{SiC}$ wafer with an etched cavity. Scanning electron microscope (SEM) characterization and the tensile test are performed for evaluating the direct bonding quality. Since both the diaphragm and the substrate are composed of single crystal $\mathrm{SiC}$ and the bonding is performed without using any intermediate material, sensor failure attributed to thermal expansion mismatch and internal stress can be effectively avoided. In addition, the proposed all-SiC sensor can realize batch-production. Ultimately, the sensing capability of the as-fabricated sensor has been demonstrated and tested over a pressure range of $0 \mathrm{kPa}$ to $800 \mathrm{kPa}$.

\section{Design and principle of operation}

Figure 1 schematically illustrates the configuration of the proposed $\mathrm{SiC}$ sensor and the transducing mechanism based on the EFPI sensing method. The size of the sensor head is $8 \mathrm{~mm} \times 8 \mathrm{~mm} \times$ $0.555 \mathrm{~mm}$, and the multi-mode optical fiber is connected to the back of the sensor through an adhesive. The core and cladding of the multimode fiber have diameters of $62.5 \mu \mathrm{m}$ and $125 \mu \mathrm{m}$,

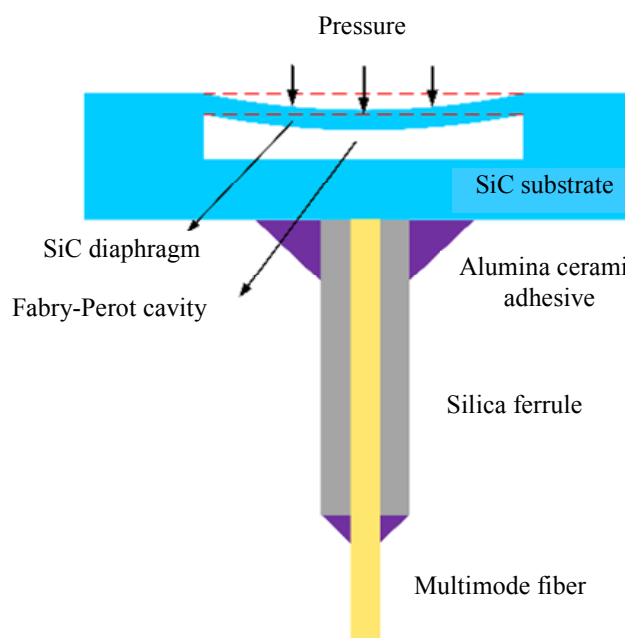

(a)
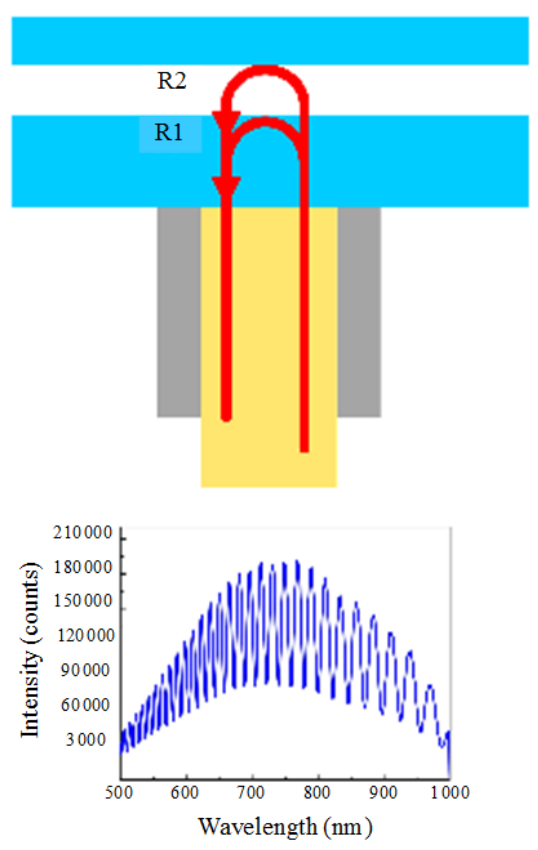

(b)

Fig. 1 Sensor configuration and principle of operation: (a) schematic of the $\mathrm{SiC}$ fiber-optic pressure sensor and (b) FP cavity interference in the sensor and the interference spectrum. 
respectively. The sensor head is formed by directly hermetical bonding of two $\mathrm{SiC}$ pieces, including a $\mathrm{SiC}$ diaphragm and a $\mathrm{SiC}$ substrate with an etched cavity with a diameter of $4 \mathrm{~mm}$. The bottom surface of the etched cavity (R1) and the inner surface of the $\mathrm{SiC}$ diaphragm (R2) form two reflective surfaces in the FP interference, as shown in Fig. 1(b). Light is passed through the optical fiber and partially reflected at the $\mathrm{R} 1$ reflective surface. The remaining light propagates through the air gap between the reflective surfaces of $\mathrm{R} 1$ and $\mathrm{R} 2$ and is reflected at the $\mathrm{R} 2$ reflective surface. The two reflections then propagate back through the same fiber and generate interference fringes. The resulting light signal is then transmitted into the detector where the signal is demodulated to determine the FP cavity length.

The intensity of the reflected light can be expressed as [17]

$$
I(k)=I_{0}(k) \cdot\left[1+\cos \left(2 k L+\varphi_{0}\right)\right]
$$

where $k=2 \pi / \lambda$ is the optical wave number, $\lambda$ is the wavelength of light, $I_{0}(k)$ is the background spectrum of the broadband source, $L$ is the FP cavity length, and $\varphi_{0}$ is the constant phase term related to the multimode excitation of the FP cavity. Based on (1), $L$ can be extracted from the corresponding spectrum.

When a uniformly distributed external pressure

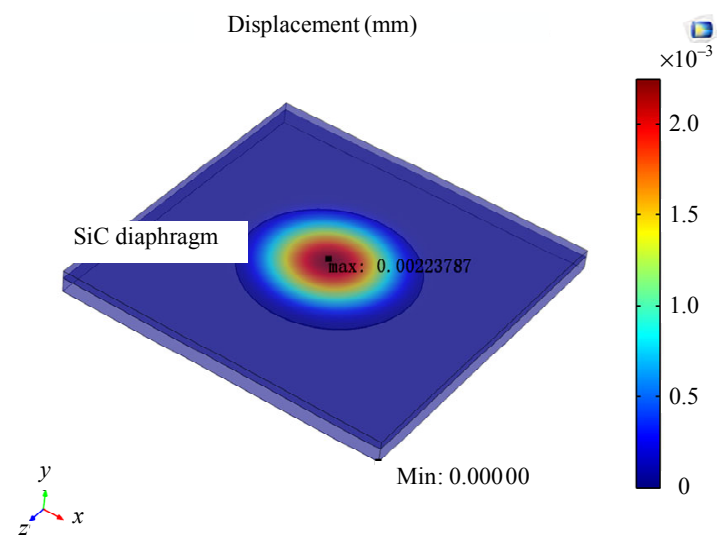

(a) is applied to the diaphragm, the diaphragm deforms and the FP cavity length changes. According to the theory of elastic mechanics, the central deflection $y$ of the sensitive diaphragm with an applied external pressure can be expressed as [16]

$$
y=\frac{3 \operatorname{Pr}^{4}\left(1-v^{2}\right)}{16 E t^{3}}
$$

where $P$ is the external pressure, $E$ is the Young modulus, $v$ is the Poisson's ratio, and $r$ and $t$ are the radius and thickness of the membrane, respectively. Therefore, the external pressure can be measured by detecting the change in the length of the FP cavity.

Finite element simulation of the proposed sensor is performed by the COMSOL software to understand deflection response of the $\mathrm{SiC}$ diaphragm over a range of pressures. The sensitive model unit size is $8 \mathrm{~mm} \times 8 \mathrm{~mm}$, the thickness of the $\mathrm{SiC}$ substrate is $355 \mu \mathrm{m}$, the thickness of the $\mathrm{SiC}$ diaphragm is $200 \mu \mathrm{m}$, and the diameter and depth of the FP cavity are $4 \mathrm{~mm}$ and $15 \mu \mathrm{m}$, respectively. Figure 2 shows the displacement deflection of the $\mathrm{SiC}$ diaphragm at an external pressure of $2 \mathrm{MPa}$. Figure 2(b) clearly shows the change in displacement in the central axis of the the SiC sensitive diaphragm. It can be seen that the maximum deflection of about $2.2 \mu \mathrm{m}$ occurs at the center of the diaphragm.

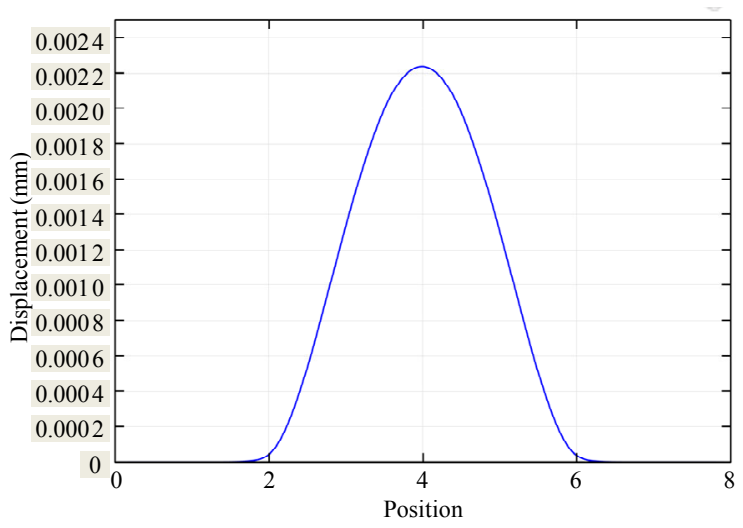

(b)

Fig. 2 Simulation of the $\mathrm{SiC}$ sensor model: (a) displacement simulation of $\mathrm{SiC}$ diaphragm under external pressure and (b) displacement distribution in the central axis of the diaphragm. 


\section{Sensor fabrication}

\subsection{SiC etching}

A double-side polished 3-inch $\mathrm{SiC}$ wafer with the thickness of $355 \mu \mathrm{m}$ and root-mean-square roughness of $\sim 0.48 \mathrm{~nm}$ ( $\mathrm{Si}$ surface) is employed in the $\mathrm{SiC}$ wafer etching process. The manufacturing process flow of the $\mathrm{SiC}$ cavity is schematically depicted in Fig. 3. To begin with the process, photoresist is spin-coated and photopatterned on the $\mathrm{SiC}$ substrate, as shown in Figs. 3(a) and 3(b). Subsequently, a $50 \mathrm{~nm}$ Cr metal film and a $200 \mathrm{~nm}$ $\mathrm{Cu}$ metal film are sputtered on the $\mathrm{SiC}$ wafer by using a magnetron sputtering device (Denton Vacuum, EXPLORER) as an adhesion layer and a seed layer, respectively [Figs.3(c) and 3(d)]. After that, stripping is performed by immersing the $\mathrm{SiC}$ wafer in an acetone solution for sonication. In this way, the photoresist and the metal covering the photoresist can be removed to expose the area to be etched [Fig.3(e)]. In order to etch a deeper cavity, a Ni metal layer with the thickness of $2.5 \mu \mathrm{m}$ is electroplated on the $\mathrm{SiC}$ substrate as an etching mask by placing the wafer into the $\mathrm{Ni}$ plating solution, as exhibited in Fig. 3(f). Then, the SiC wafer is loaded into a magnetic neutral loop discharge (NLD) plasma device for etching. In the NLD etching step, the parameters are as follows: $\mathrm{SF}_{6}$ and $\mathrm{O}_{2}$ with gas flows of $120 \mathrm{sccm}$ and $50 \mathrm{sccm}$, pressure of $0.67 \mathrm{~Pa}, \mathrm{RF}$ power of $1250 \mathrm{~W}$, and bias power of $250 \mathrm{~W}$. After etching for $20 \mathrm{~min}$, a series of shallow cylindrical cavities with the $4 \mathrm{~mm}$ diameter are etched on the $\mathrm{SiC}$ wafer [Fig. $3(\mathrm{~g})]$. Finally, $\mathrm{Ni}$ etching solution ( $\left.\mathrm{HCl}: \mathrm{HNO}_{3}: \mathrm{H}_{2} \mathrm{O}=3: 1: 2\right), \quad \mathrm{Cu}$ etching solution ( $\left.\mathrm{HF}: \mathrm{HNO}_{3}=1: 1\right)$, and $\mathrm{Cr}$ etching solution $(22 \%$ ammonium cerium nitrate: $8 \%$ acetic acid: $70 \% \mathrm{H}_{2} \mathrm{O}$ ) are used to remove the remaining metal mask [Fig. 3(h)]. After removing the mask, the depths of the etched cavities are tested by a step meter to be $14 \mu \mathrm{m}-15 \mu \mathrm{m}$.

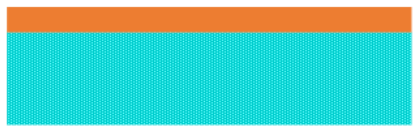

(a)

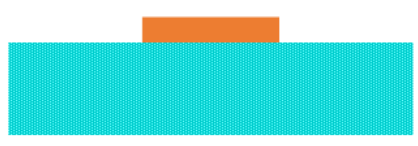

(b)

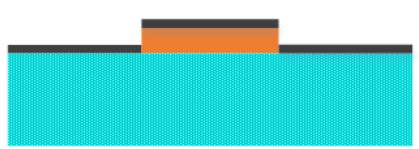

(c)

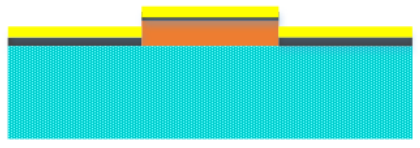

(d)

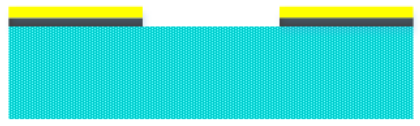

(e)

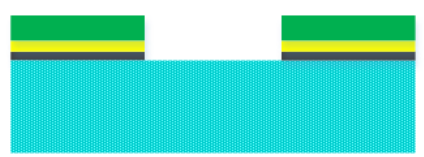

(f)

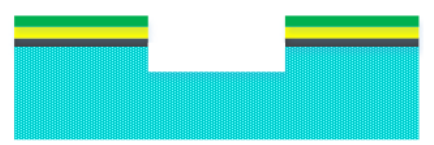

(g)

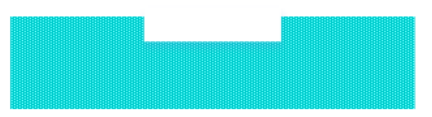

(h)

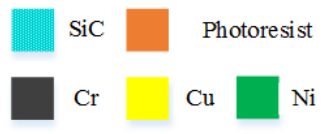

Fig. 3 Etching process flow chart of the SiC cavity by NLD: (a) coating photoresist, (b) patterning by photolithography, (c) sputtering $\mathrm{Cr}(50 \mathrm{~nm})$, (d) sputtering $\mathrm{Cu}(200 \mathrm{~nm})$, (e) stripping, (f) electroplating $\mathrm{Ni}(2.5 \mu \mathrm{m})$, (g) etching SiC cavity by NLD, and (h) remove remaining mask.

\subsection{SiC direct bonding}

Prior to direct bonding, the $\mathrm{SiC}$ wafer with etched cavities is cut into $8 \mathrm{~mm} \times 8 \mathrm{~mm}$ square pieces in order to reduce surface warpage. A flat $\mathrm{SiC}$ wafer is thinned to $200 \mu \mathrm{m}$ as a $\mathrm{SiC}$ diaphragm to mate with the etched sheet. SiC direct wafer bonding mainly includes three main steps: (1) wafer surface cleaning, (2) wafer plasma activation and pre-bonding, and (3) wafer high temperature bonding. Since surface cleaning is critical to the success of $\mathrm{SiC}$ direct bonding and the corrosion 
resistance of $\mathrm{SiC}$, the surface wet chemical cleaning is performed according to the following cleaning method. First, the samples are immersed in the sulfuric /peroxide mixture (SPM) $\left(\mathrm{H}_{2} \mathrm{SO}_{4}: \mathrm{H}_{2} \mathrm{O}_{2}=3: 1\right)$ at $120{ }^{\circ} \mathrm{C}$ for $20 \mathrm{~min}$ to remove the organic and metallic impurities, followed by soaking in a mixed solution $\left(\mathrm{NH}_{3} \mathrm{H}_{2} \mathrm{O}: \mathrm{H}_{2} \mathrm{O}_{2}: \mathrm{H}_{2} \mathrm{O}=1: 2: 7\right)$ at $75{ }^{\circ} \mathrm{C}$ for $20 \mathrm{~min}$ to remove the particles. At the final stage of cleaning, the $\mathrm{SiC}$ wafers are dipped again in the mixture of $\mathrm{H}_{2} \mathrm{SO}_{4}$ and $\mathrm{H}_{2} \mathrm{O}_{2}$ for the hydrophilic treatment. After then, all the samples are rinsed using de-ionized water and blow-dried using high pure nitrogen.

For achieving hydrophilic pre-bonding of the $\mathrm{SiC}$ wafers, the cleaned $\mathrm{SiC}$ pieces are introduced to the plasma system (PVA Tepla IoN40) for surface activation by oxygen plasma. Parameters in this activation process are as follows, power of $200 \mathrm{~W}$, chamber pressure of 200 mTorr, and activation duration of $45 \mathrm{~s}$. Subsequently, the paired $\mathrm{SiC}$ pieces are dipped in methanol with a higher $-\mathrm{OH}$ concentration to increase the amount of hydroxyl groups on the wafers. Then, the paired $\mathrm{SiC}$ wafers are brought into contact immediately in air with their crystalline axes aligned. After the pre-bonding, the bonding strength is very low due to the paired $\mathrm{SiC}$ wafers being held together via hydrogen bonds and the polar $-\mathrm{OH}$ groups. To enhance the bonding strength, the pre-bonded samples are loaded into a graphite die, as shown in Fig.4, and introduced into a high-temperature hot-press furnace with an ultimate vacuum of $5 \times 10^{-3} \mathrm{~Pa}$ for high-temperature bonding. The direct bonding temperature curve of the pre-bonded $\mathrm{SiC}$ pieces is illustrated in Fig. 5. The temperature is raised from room temperature to $200{ }^{\circ} \mathrm{C}$ at a heating rate of $10^{\circ} \mathrm{C} / \mathrm{min}$ and then heated to $1400^{\circ} \mathrm{C}$ at a heating rate of $15^{\circ} \mathrm{C} / \mathrm{min}-20^{\circ} \mathrm{C} / \mathrm{min}$ for $2 \mathrm{~h}$. During the holding period, a pressure of $4 \mathrm{MPa}$ is applied on the paired wafers. The SiC sample after high temperature bonding is shown in Fig. 5, and visual inspection reveals that all contacted areas of two $\mathrm{SiC}$ pieces are tightly bonded together with no sign of voids or cracks.

After direct bonding, the multimode fiber is cleaved and inserted into a silica ferrule, and vertically glued on the back surface of the $\mathrm{SiC}$ sensor by alumina ceramic adhesive.
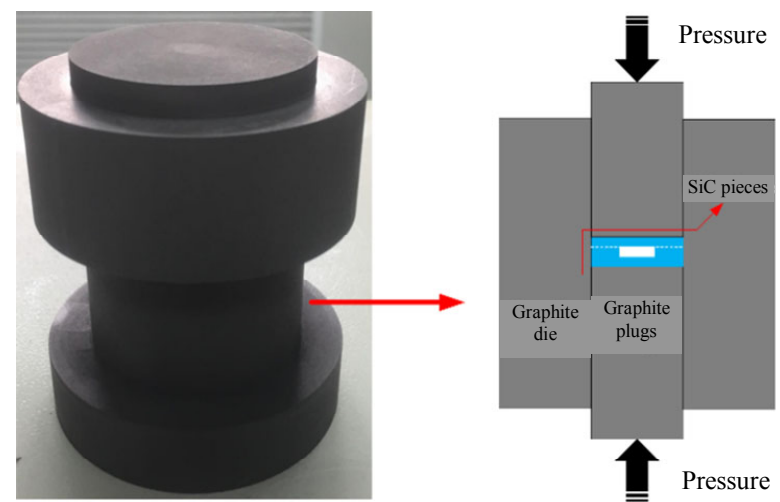

Fig. 4 Photograph of the graphite die and the bonded $\mathrm{SiC}$ sample.

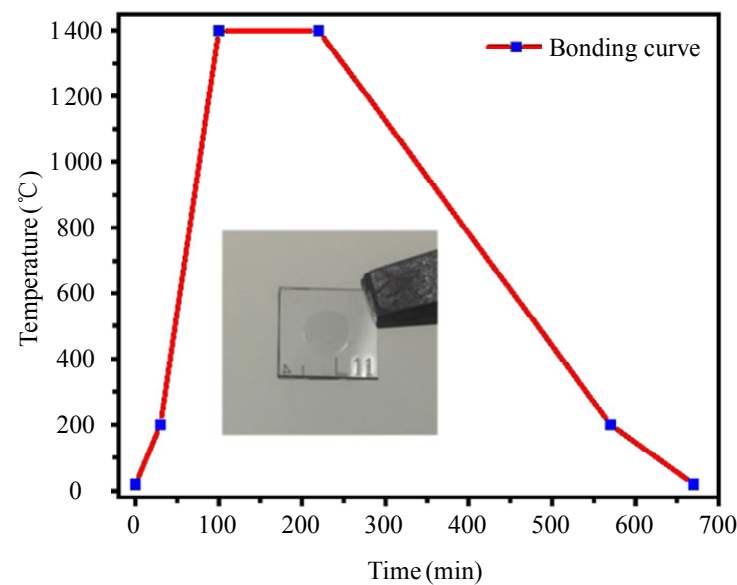

Fig. $5 \mathrm{SiC}$ high temperature direct bonding curve.

\section{Results and discussion}

\subsection{SEM characterization}

In order to observe the internal structure of the SiC sample, SEM observation is performed after etching and direct bonding. Figure 6 shows the surface and cross section of the $\mathrm{SiC}$ wafer after etching. Figure 6(a) shows that the bottom surface of the etched cavity is flat and smooth, which can meet the requirements of optical flatness. It can be clearly seen from Figs. 6(c) and 6(d) that the sidewall of the etching cavity is smooth and has a very good verticality with an angle of about $92.2^{\circ}$. The depth 
of the etched cavity is approximately $14.83 \mu \mathrm{m}$, which is consistent with previous step measurements.

To further investigate the internal quality of the direct bonding interface, the bonded SiC sample is cut along the cross section using an ultraviolet laser and observed under an SEM, as shown in Fig. 7. Surprisingly, the bonding interface is not clearly visible, indicating that the two $\mathrm{SiC}$ sheets have been fused into one another after high temperature bonding. Moreover, the FP cavity formed by $\mathrm{SiC}$ direct bonding is intact and still keeps at a height of about $15 \mu \mathrm{m}$, as illustrated in Fig.7(b). In addition, the elements analysis of the direct bonding interface by energy dispersive spectrometer (EDS) attached to the SEM is performed, as shown in Fig. 8. The elemental composition is carbon, silicon, and gold, and the presence of the gold element is attributed to the sputtered gold film for the SEM cross section observation.

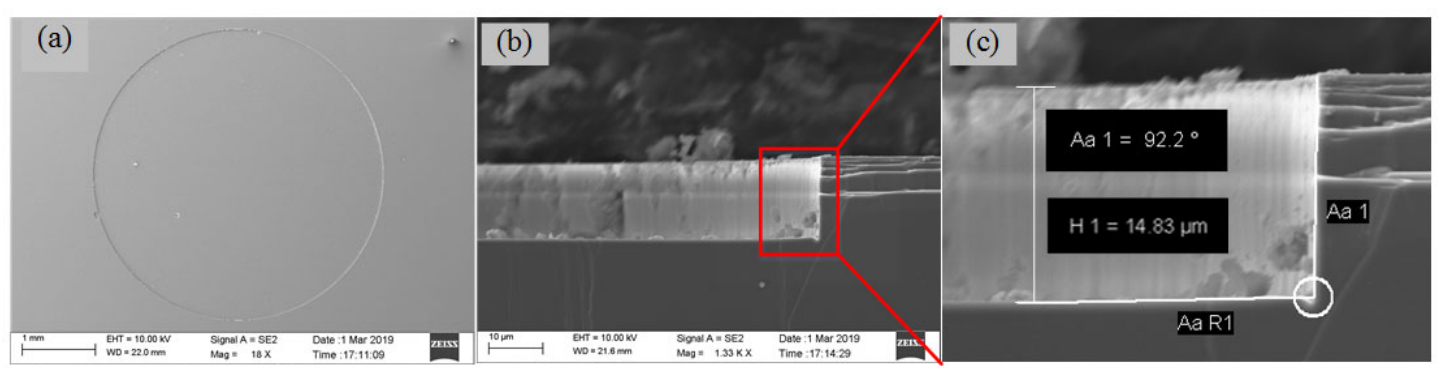

Fig. 6 SEM images of the SiC cavity by NLD.

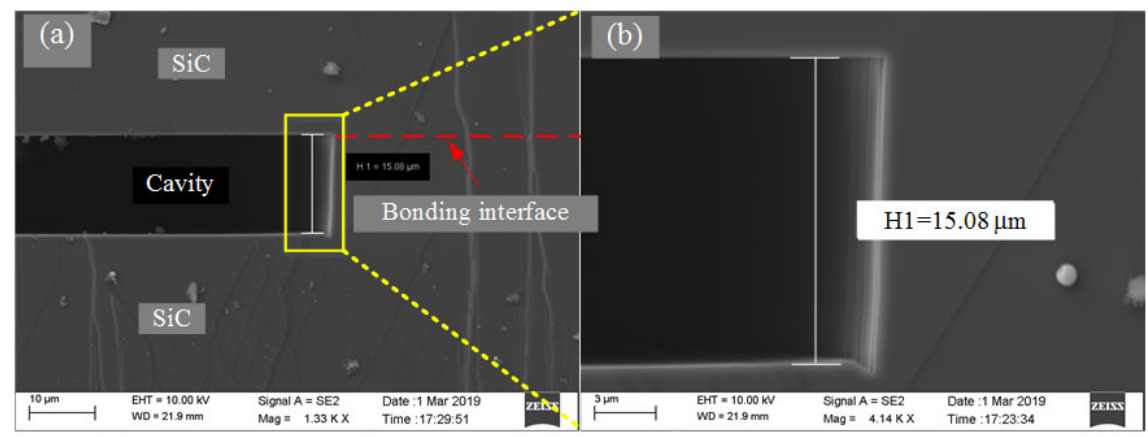

Fig. 7 SEM images of the SiC direct bonding interface.

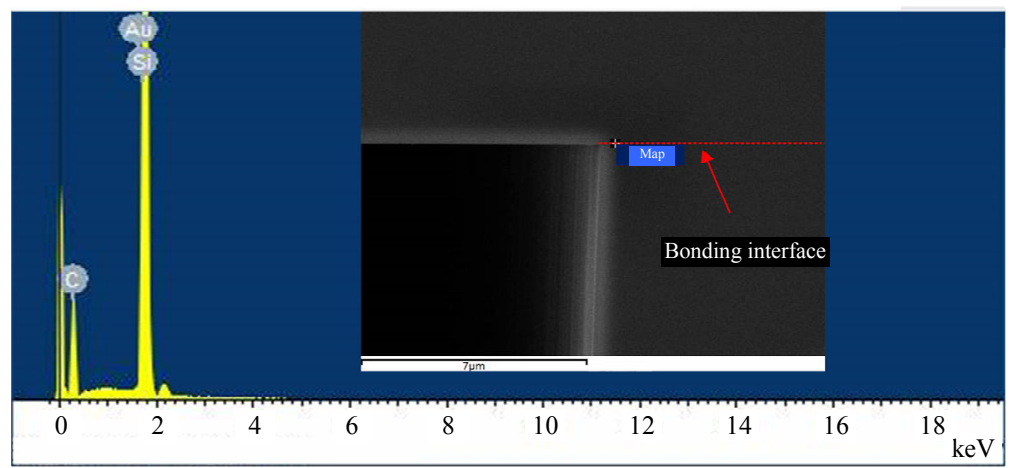

Fig. 8 EDS analysis of the SiC direct bonding interface.

\subsection{Bonding strength}

For evaluating the bonding strength of the $\mathrm{SiC}$ bonded sample, a tensile measurement is performed using the tensile tester (Instron 2710, $50 \mathrm{kN}$ ). As shown in Fig. 9(a), the bonded $\mathrm{SiC}$ samples are glued to the vertical jigs on both sides and then loaded into a tensile tester for testing. The fracture 
position is located at the direct bonding interface, as exhibited in Fig.9(c). And the bonding strength of 6.25 MPa is achieved for the $\mathrm{SiC}$ direct bonded sample. This value exceeds the minimum bond strength (4 $\mathrm{MPa}-5 \mathrm{MPa}$ ) required for micro electromechanical system (MEMS) device fabrication. Furthermore, the bonding strength and sealing performance of the bonded $\mathrm{SiC}$ sample have been successfully demonstrated by applying them to a pressure test at room temperature in the following section.

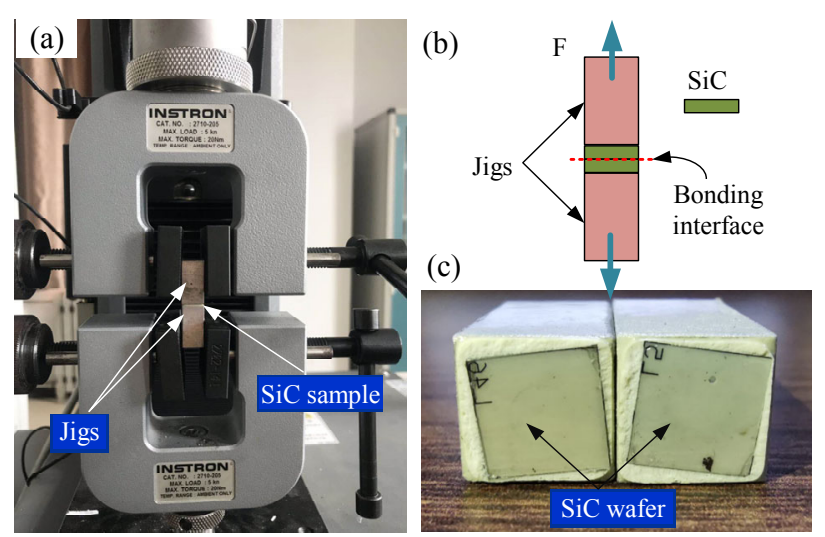

Fig. 9 Tensile test of $\mathrm{SiC}$ direct bonded sample.

\subsection{Pressure response test}

To demonstrate pressure measurement, the white-light interference system for sensor interrogation is constructed by using the configuration shown in Fig. 10. The optical interrogation system is briefly configured by a halogen lamp light source, a $3 \mathrm{~dB}$ fiber coupler, and an ocean optics spectrometer. The broadband light from the halogen lamp propagates along the fiber and delivers to the FP cavity of the sensor, and the interference signal is routed back to the ocean optics spectrometer for measurement via a $3 \mathrm{~dB}$ fiber coupler. Spectral interrogation and frequencyestimation-based signal-processing algorithm [27] are used to process the interference signal to demodulate the FP cavity length. During testing, the sensor is placed in a sealed pressure chamber through a fiber optic adapter. The pressure in the chamber is controlled by an air pump and a pressure regulator. When the pressure in the pressure chamber increases, the cavity length of the proposed sensor reduces. Consequently, the pressure can be measured by monitoring the cavity length change.

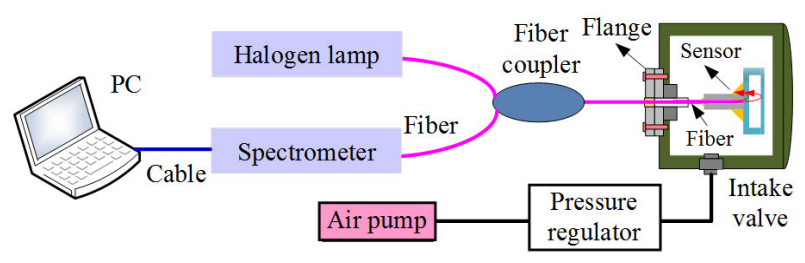

Fig. 10 Schematic of the pressure measurement system.

Figure 11 depicts the sensor performance at room temperature and under high temperature environments. Figure 11(a) shows the curves of the FP cavity length response to external pressure during three loading pressure experiments at room temperature under $0 \mathrm{kPa}-800 \mathrm{kPa}$. It can be noted that the pressure response curves exhibit a good repeatability and the error is approximately $1.42 \%$. Figure 11(b) shows sensor pressure response curves for loading and unloading pressure conditions over three cycles. It can be observed that the cavity length changes linearly with the pressure over the entire test range and exhibits a good recoverability. The sensor returns to the same initial cavity length of $14.766 \pm 0.010 \mu \mathrm{m}$ (maximum variation) at approximately $0 \mathrm{kPa}$ after each cycle. The pressure sensitivities of three tests are $1.84 \mathrm{~nm} / \mathrm{kPa}$, $1.83 \mathrm{~nm} / \mathrm{kPa}$, and $1.83 \mathrm{~nm} / \mathrm{kPa}$ in the pressure range of $0 \mathrm{kPa}-800 \mathrm{kPa}$. And the maximum hysteresis error is $0.41 \%$. In addition, the sensor is retained at $800 \mathrm{kPa}$ for $15 \mathrm{~h}$, and its cavity length shows no significant drift. This long-term test of sensing cavity leakage, coupled with the phenomenon that the sensor returns to the initial cavity length after each test cycle, indicates that the bonded cavity is tightly sealed. In addition, the high temperature performance of the sensor is verified under temperature-pressure composite environments. Figure 11(c) shows the sensor pressure response curves at $23{ }^{\circ} \mathrm{C}-400{ }^{\circ} \mathrm{C}$ under $0 \mathrm{kPa}-800 \mathrm{kPa}$. The results show that the cavity length changes linearly with pressure at different temperatures. The sensitivity of the sensor remains approximately 
unchanged, with a value of $1.84 \mathrm{~nm} / \mathrm{kPa}$. Also, the initial cavity length exhibits temperature dependence, plotted against temperature, as shown in Fig. 11(d). We can observe that the initial cavity length of the sensor increases with increasing temperature, and the cavity length changes approximately linearly with the temperature with a coefficient of

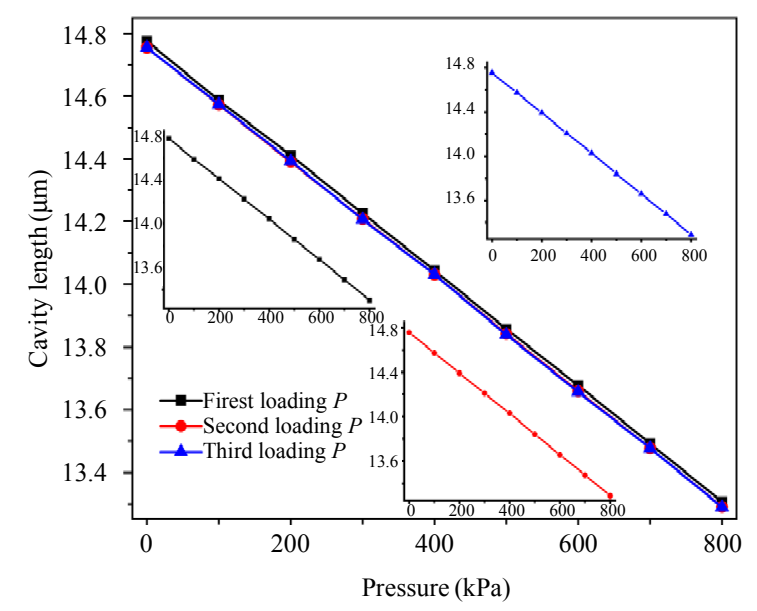

(a)

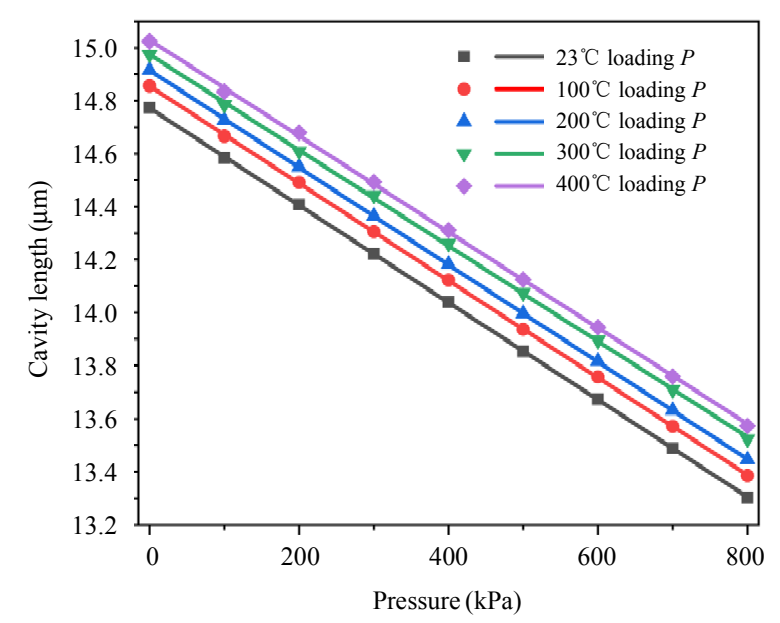

(c)
$0.617 \mathrm{~nm} /{ }^{\circ} \mathrm{C}$, which is mainly caused by the thermal expansion of the $\mathrm{SiC}$ material. Finally, in order to explore the stability of the sensor under high temperature environments, the sensor is retained at $400{ }^{\circ} \mathrm{C}$ and $0 \mathrm{kPa}$ for $30 \mathrm{~min}$. The curve of the cavity length versus time is shown in the inset of Fig. 11(d), and the cavity length has no significant change.

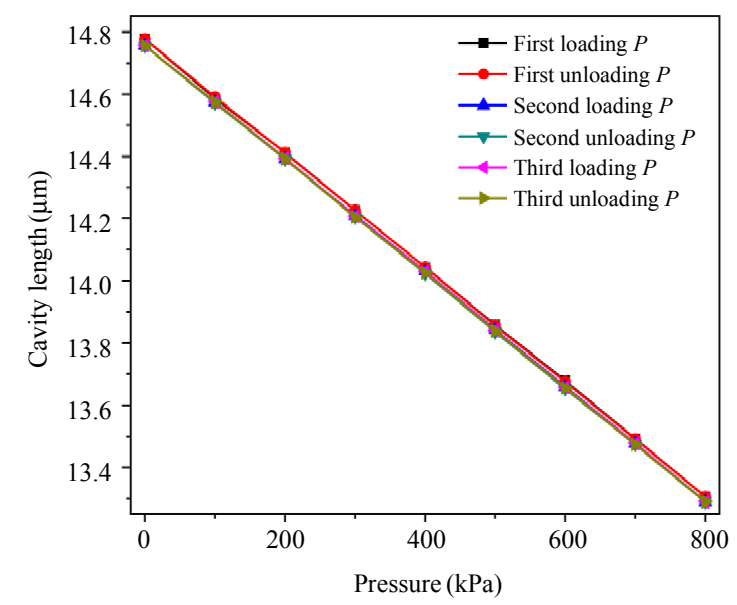

(b)

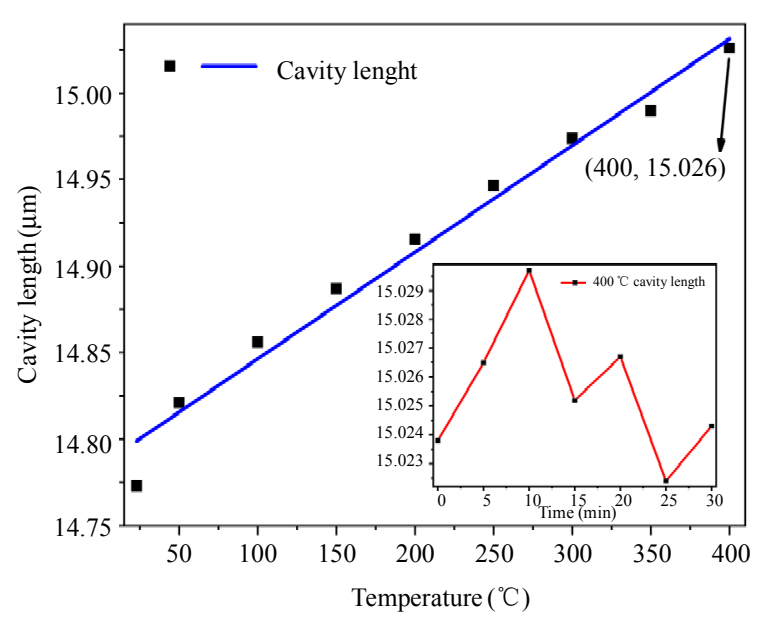

(d)

Fig. 11 Test results of the fabricated sensor: (a) curves of the FP cavity length response to external pressure during three loading pressure experiments, (b) sensor pressure response curves for loading and unloading pressure conditions over three cycles, (c) sensor pressure response curves at $23{ }^{\circ} \mathrm{C}-400{ }^{\circ} \mathrm{C}$ temperature and under $0 \mathrm{kPa}-800 \mathrm{kPa}$ pressure, and (d) FP cavity length as a function of temperature under $0 \mathrm{kPa}$ pressure.

\section{Conclusions}

In this study, an all-SiC sensor structure for pressure test is proposed and demonstrated. The sealed pressure cavity is fabricated by a combination of NLD etching of the $\mathrm{SiC}$ wafer and $\mathrm{SiC}$ direct wafer boding. SEM characterization indicates that the sidewall of the etching cavity is smooth and has a very good verticality. In addition, the cavity structure after direct wafer bonding remains intact and the interface has a good bonding quality. The tensile test indicates that the bonding strength of $\mathrm{SiC}$ wafer direct boding reaches $6.25 \mathrm{MPa}$. The white-light interference system for sensor 
interrogation is constructed, and the pressure sensor displays a good linear response in the range of $0 \mathrm{kPa}-800 \mathrm{kPa}$, with a repeatability error of $1.42 \%$ at room temperature. The high-temperature test results of the $\mathrm{SiC}$ sensor show that the sensor can work stably under high temperature environments up to $400{ }^{\circ} \mathrm{C}$. In the future, the non-contact measurement method will be used to avoid the influence of high-temperature ceramic adhesive on the temperature resistance of the sensor, thereby increasing the operating temperature of the $\mathrm{SiC}$ sensor.

Open Access This article is distributed under the terms of the Creative Commons Attribution 4.0 International License (http://creativecommons.org/licenses/by/4.0/), which permits unrestricted use, distribution, and reproduction in any medium, provided you give appropriate credit to the original author(s) and the source, provide a link to the Creative Commons license, and indicate if changes were made.

\section{Acknowledgment}

This work was supported by the National Natural Science Foundation of China (Grant No. 51935011), the fund for Shanxi "1331 Project" Key Subject Construction, Shanxi Natural Science Foundation (Grant Nos. 201801D121157 and 201801D221203), and Scientific and Technological Innovation Programs of Higher Education Institutions in Shanxi (Grant No. 1810600108MZ).

\section{References}

[1] W. J. Pulliam, R. S. Fielder, and P. M. Russler, "High-temperature high-bandwidth fiber optic MEMS pressure-sensor technology for turbine engine component testing," SPIE, 2002, 4578: 229-238.

[2] Y. Z. Zhu, K. L. Cooper, G. R. Pickrell, and A. B. Wang, "High-temperature fiber-tip pressure sensor," Journal of Lightwave Technology, 2006, 24(2): 861-869.

[3] R. S. Okojie, D. Lukco, V. Nguyen, and E. Savrun, " $4 \mathrm{H}-\mathrm{SiC}$ piezoresistive pressure sensors at $800{ }^{\circ} \mathrm{C}$ with observed sensitivity recovery," IEEE Electron Device Letters, 2015, 36(2): 174-176.
[4] Z. Yao, T. Liang, P. G. Jia, Y. P. Hong, L. Qi, C. Lei, et al., "A high-temperature piezoresistive pressure sensor with an integrated signal-conditioning circuit," Sensors, 2016, 16(6): 913.

[5] J. Ren, M. Ward, P. Kinnell, R. Craddock, and X. Y. Wei, "Plastic deformation of micromachined silicon diaphragms with a sealed cavity at high temperatures," Sensors, 2016, 16(2): 204.

[6] H. P. Phan, H. H. Cheng, T. Dinh, B. Wood, T. K. Nguyen, F. Mu, et al., "Single-crystalline 3C-SiC anodically bonded onto glass: an excellent platform for high-temperature electronics and bioapplications," ACS Applied Materials \& Interfaces, 2017, 9(33): 27365-27371.

[7] F. W. Mu, Y. H. Wang, R. He, and T. Suga, "Direct wafer bonding of $\mathrm{GaN}-\mathrm{SiC}$ for high power GaN-on-SiC devices," Materialia, 2018, 3: 12-14.

[8] N. Marsi, B. Y. Majlis, A. A. Hamzah, and F. M. Yasin, "A MEMS packaged capacitive pressure sensor employing 3C-SiC with operating temperature of $500{ }^{\circ} \mathrm{C}$," Microsystem Technologies, 2015, 21(1): 9-20.

[9] T. K. Nguyen, H. P. Phan, T. Dinh, K. M. Dowling, A. R. M. Foisal, D. G. Senesky, et al., "Highly sensitive 4H-SiC pressure sensor at cryogenic and elevated temperatures," Materials \& Design, 2018, 156: 441-445.

[10] G. Wieczorek, B. Schellin, E. Obermeier, G. Fagnani, and L. Drera, "SiC based pressure sensor for high-temperature environments," IEEE Sensors, 2007, 28: 748-751.

[11] L. Beker, A. Maralani, L. W. Lin, and A. P. Pisano, "Modeling, fabrication, and characterization of $\mathrm{SiC}$ concentrically matched differential capacitance output pressure sensors," Sensors and Actuators A: Physical, 2018, 273: 293-302.

[12] N. Marsi, B. Y. Majlis, A. A. Hamzah, and F. M. Yasin, "Development of high temperature resistant of $500{ }^{\circ} \mathrm{C}$ employing silicon carbide (3C-SiC) based MEMS pressure sensor," Microsystem Technology, 2015, 21(2): 319-330.

[13]F. Xu, D. X. Ren, X. L. Shi, C. Li, W. W. Liu, L. Lu, et al., "High-sensitivity Fabry-Perot interferometric pressure sensor based on a nanothick silver diaphragm," Optics Letters, 2012, 37(2): 133-135.

[14] J. Ma, W. Jin, H. L. Ho, and J. Y. Dai, "High-sensitivity fiber-tip pressure sensor with graphene diaphragm," Optics Letters, 2012, 37(13): 2493-2495.

[15] W. H. Wang, N. Wu, Y. Tian, C. Niezrecki, and X. W. Wang, "Miniature all-silica optical fiber pressure sensor with an ultrathin uniform diaphragm," Optics Express, 2010, 18(9): 9006-9014.

[16] T. G. Liu, J. D. Yin, J. F. Jiang, K. Liu, S. Wang, and S. L. Zou, "Differential-pressure-based fiber-optic temperature sensor using Fabry-Perot interferometry," Optics Letters, 2015, 40(6): 
1049-1052.

[17] J. Yi, E. Lally, A. B. Wang, and Y. Xu, "Demonstration of an all-sapphire Fabry-Pérot cavity for pressure sensing," IEEE Photonics Technology Letters, 2010, 23: 9-11.

[18] Y. N. Zhang, L. Yuan, X. W. Lan, A. Kaur, J. Huang, and H. Xiao, "High-temperature fiber-optic Fabry-Perot interferometric pressure sensor fabricated by femtosecond laser: erratum," Optics Letters, 2014, 39(1): 4609-4612.

[19]F. Ceyssens, M. Driesen, and R. Puers, “An optical absolute pressure sensor for high-temperature applications, fabricated directly on a fiber," Journal of Micromechanics and Microengineering, 2009, 19(11): 115017.

[20] S. Pevec and D. Donlagic, "Miniature fiber-optic sensor for simultaneous measurement of pressure and refractive index," Optics Letters, 2014, 39(21): 6221-6224.

[21] J. C. Xu, X. W. Wang, K. L. Cooper, and A. B. Wang, "Miniature all-silica fiber optic pressure and acoustic sensors," Optics Letters, 2005, 30(24): 3269-3271.

[22] C. R. Liao, S. Liu, L. Xu, C. Wang, Y. P. Wang, Z. Y. $\mathrm{Li}$, et al., "Sub-micron silica diaphragm-based fiber-tip Fabry-Perot interferometer for pressure measurement," Optics Letters, 2014, 39(10): 2827-2830.

[23]Z. Li, P. G. Jia, G. C. Fang, H. Liang, T. Liang, W. Y. Liu, et al., "Microbubble-based fiber-optic Fabry-Perot pressure sensor for high-temperature application," Applied Optics, 2018, 57(8): 1738-1743.

[24] S. Liu, Y. P. Wang, C. R. Liao, Y. Wang, J. He, C. L. Fu, et al., "Nano silica diaphragm in-fiber cavity for gas pressure measurement," Scientific Reports, 2017, 7(1): 787.

[25] W. Pulliam, P. Russler, R. Mlcak, K. Murphy, and C. Kozikowski, "Micromachined, SiC fiber optic pressure sensors for high-temperature aerospace applications," SPIE, 2000, 30(21): 4202.

[26] Y. G. Jiang, J. Li, Z. W. Zhou, X. G. Jiang, and D. Y. Zhang, "Fabrication of all-SiC fiber-optic pressure sensors for high-temperature applications," Sensors, 2016, 16(10): 1660.

[27]F. B. Shen and A. B. Wang, "Frequencyestimation-based signal-processing algorithm for white-light optical fiber Fabry-Perot interferometers," Applied Optics, 2005, 44(25): 5206. 